\author{
Hans C. Peyer
}

\title{
Ehrung und Würdigung bei der SANTH
}

\section{Andreas Beck wird Ehrenpräsident der Schweizerischen Ärztegesellschaft für Neuraltherapie nach Hunecke}

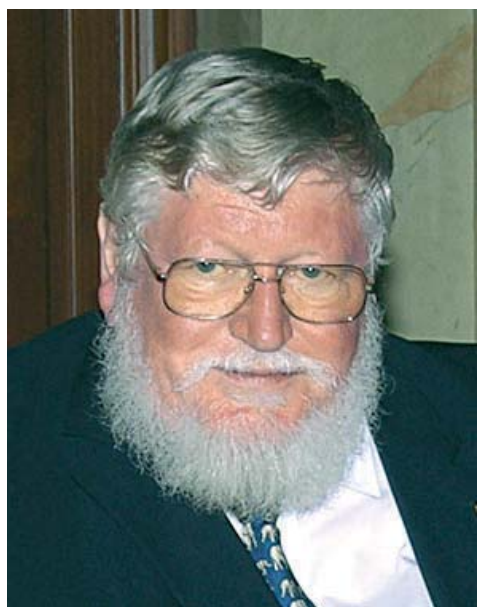

Dr. med. Andreas Beck

ler) begann er neben seiner intensiven Praxistätigkeit mit der Ausbildung junger Kollegen in Neuraltherapie und gründete 1986 die Schweizerische Ärztegesellschaft für Neuraltherapie nach Huneke, deren Präsident er bis zum heutigen Tag, also während 23 Jahren, geblieben ist. Seine rege Vortragstätigkeit und sein unermüdlicher Kampf um Anerkennung haben ihn nie ruhen lassen, er ist sich seines Auftrages sicher geblieben: Bevor Qualitätssicherung zum Schlagwort wurde, hat er durchgesetzt, dass in den grösseren komplementärmedizinischen Gesellschaften unter dem Dach der SAGEM nach Ausbildungs- und Prüfungsordnungen vorgegangen wird, was schliesslich auch zur Anerkennung durch die FMH (Fähigkeitsausweis Neuraltherapie) geführt hat. Als Exponent dieser Methode war er massgeblich an der Schaffung eines Ordinariates an der Universität Bern beteiligt. Im Rahmen der kollegialen Instanz für Komple- mentärmedizin KIKOM hat er bis Ende des Wintersemesters 2001/2002 die Lehrtätigkeit für Neuraltherapie innegehabt.

Mit seiner aktiven Teilnahme an Kongressen im In- und Ausland ist es Dr. Beck gelungen, Kontakte zu namhaften Persönlichkeiten aufzubauen und führende Vertreter komplementärmedizinischer Fachrichtungen zu Vorträgen und Kursen in die Schweiz zu holen. Für seine ganz besonderen Verdienste um die Neuraltherapie erhielt er im Jahre 1993 in Freudenstadt die Huneke-Medaille der internationalen Gesellschaft für Neuraltherapie.

\section{Gründungsmitglied bei SAGEM und UNION}

Als Gründungsmitglied der SAGEM, langjähriger Präsident und heutiger Ehrenpräsident derselben, hat er einen grossen Beitrag zur fundierten Ausbildung geleistet, wobei es ihm stets ein Anliegen war, offen zu sein für das Neue, sich damit auseinander zu setzen und die Anwendung in eigener Erfahrung zu praktizieren. Als mächtiger Streiter hat er viele Vorreiterrollen übernommen und sich mit Beharrlichkeit in zahlreichen Gremien eingesetzt nach dem Motto: „Alle gemeinsam für die gute Sache“. Dieser Beharrlichkeit verdanken wir letztlich auch das Entstehen der UNION schweizerischer komplementärmedizinischer Ärzteorganisationen. Er war 1996 Mitbegründer der UNION und bis heute im Vorstand aktiv. Als Mitglied der eidgenössischen Leistungskommission ELK und Vizepräsident im ECPM hat er sich mit Engagement um die Stellung der Komplementärmedizin eingesetzt. Als akti- 
ver Mitdenker im Lenkungsausschuss zur Volksinitiative „Ja zur Komplementärmedizin“ konnte er zusammen mit uns allen das erfreuliche Abstimmungsresultat vom 17. Mai dieses Jahres miterleben. Zahlreiche ausländische Gesellschaften für Neuraltherapie haben ihn als Ehrenmitglied aufgenommen, so die Deutsche Ärztegesellschaft für Akupunktur und Neuraltherapie, die belgische und die portugiesische Neuraltherapiegesellschaft. Von Franz Hopfer hat er die Organisation und Leitung der Silser Woche für Neuraltherapie übernommen, sie findet jeweils Ende Januar im Engadin statt und erfreut sich grosser Beliebtheit, auch unter Kollegen des benachbarten Auslandes.

Lieber Andi: Wir - Freunde, Kollegen, Mitstreiter und Gesellschaftsmitglieder - sind Dir für Deinen grossen und selbstlosen Einsatz dankbar, wir sind uns bewusst, zu welchen Durchbrüchen Du uns verholfen hast. Du bist ein Pionier der komplementären Medizin und hast dieser in der Schweiz einem Winkelried gleich Breschen geschlagen. Möge Dich der heutige Tag dazu anhalten, aus höherer Warte Rückblick zu halten, mit Stolz auf das Erreichte zu schauen und mit anhaltender Begeisterung Dich dafür einzusetzen, dass es nach all den Wirren der Vergangenheit harmonisch und doch unaufhaltsam weitergehen möge auf dem bisweilen steinigen Weg der schweizerischen Komplementärmedizin.

Wir schätzen Dich für Deinen unermüdlichen, kämpferischen, kompromisslosen und uneigennützigen Einsatz und für Dein aktives, erfolgreiches Bemühen um die Komplementärmedizin und ganz besonders um die Veran- kerung und Anerkennung der Neuraltherapie nach Huneke in der Schweiz.

Mit grosser Freude und Dank aller unter dem Dach der SANTH vereinten Neuraltherapeuten und als besondere Anerkennung um Deine einmaligen Verdienste ernenne ich Dich hiermit zum Ehrenpräsidenten der schweizerischen Ärztegesellschaft für Neuraltherapie nach Huneke.

Lieber Andi, wir danken Dir und applaudieren für Dein künftiges Wohlergehen!»

\section{Anschrift des Autors}

Dr. med. Hans C. Peyer

Präsident SAGEM

Sonnmattstrasse 23a

CH-3506 Grosshöchstetten 